\title{
Journal of Mineralogical and Petrological Sciences
}

Official journal of Japan Association of Mineralogical Sciences (JAMS), focusing on mineralogical and petrological sciences and their related fields. Journal of Mineralogical and Petrological Sciences (JMPS) is the successor journal to both "Journal of Mineralogy, Petrology and Economic Geology" and "Mineralogical Journal". Journal of Mineralogical and Petrological Sciences (JMPS) is indexed in the ISI database (Thomson Reuters), the Science Citation Index-Expanded, Current Contents/Physical, Chemical \& Earth Sciences, and ISI Alerting Services.

\section{Editorial Board Members}

\author{
Chief Editor: Masaki Enami, Nagoya University \\ Chief Handling Editors: Takao Hirajima, Kyoto University; Akira Yoshiasa, Kumamoto University
}

\begin{tabular}{ll}
\multicolumn{2}{c}{ Associate Editors: } \\
Jung Ho Ahn, Chungbuk National University, Korea & Anhuai Lu, Peking University, China \\
Richard J. Arculus, Australian National Univ., Australia & Gregory R. Lumpkin, University of Cambridge, UK \\
D. Chandrasekharam, Indian Institute of Technology, India & Hiroharu Matsueda, Hokkaido University \\
Ming Chen, Guangzhou Institute of Geochemistry, China & Takashi Murakami, the University of Tokyo \\
Moonsup Cho, Seoul National University, Korea & Michihiko Nakamura, Tohoku University \\
Mervet Elhadad, Assiut University, Egypt & Munetomo Nedachi, Kagoshima University \\
Koichiro Fujimoto, Tokyo Gakugei University & Masaaki Obata, Kyoto University \\
Kiyoshi Fujino, Hokkaido University & Eiji Ohtani, Tohoku University \\
James B. Gill, University of California Santa Cruz, USA & Hiroki Okudera, Kanazawa University \\
Ken-Ichiro Hayashi, University of Tsukuba & Tsutomu Sato, Hokkaido University \\
Akira Ishiwatari, Tohoku University & Takayuki Sawaki, Natl. Inst. Advance. Indust. Sci. Tec. \\
Motoharu Kawano, Kagoshima University & Norimasa Shimobayashi, Kyoto University \\
Alexander Khanchuk, Far East Geological Institute, Russia & Joseph R. Smyth, University of Colorado at Boulder, USA \\
Mitsuyoshi Kimata, University of Tsukuba & Kazumasa Sugiyama, Tohoku University \\
Jun-Ichi Kimura, Japan Agency Marine-Earth Sci. Tec. & Kazuhiro Suzuki, Nagoya University \\
Tetsu Kogiso, Kyoto University & Yoshihiko Tamura, Japan Agency Marine-Earth Sci. Tec. \\
M. Satish-Kumar, Shizuoka University & Kazushige Tomeoka, Kobe University \\
& Toshiaki Tsunogae, University of Tsukuba
\end{tabular}

*New! Submissions online at http://wwwsoc.nii.ac.jp/jams3/jmps.htm

Submissions by e-mail to jmps_editorial@spa.nifty.com (max: 20 MB)

For more information on this journal: http://wwwsoc.nii.ac.jp/jams3/jmps.htm

Online journal: http://www.jstage.jst.go.jp/browse/jmps

Requesting permission to reproduce JMPS material:

For requests for permission to use figures, tables or text in the JMPS, contact jmps_editorial@spa.nifty.com.

For the detailed information, visit the JMPS web site at http://wwwsoc.nii.ac.jp/jams3/jmps.htm.

Editorial Office: Journal of Mineralogical and Petrological Sciences, Japan Association of Mineralogical Sciences (JAMS), c/o Graduate School of Science, Tohoku University, Sendai 980-8578, Japan E-mail: editorial@spa.nifty.com

Subscription to Journal of Mineralogical and Petrological Sciences: Annual subscription price is US\$ 50.00 (6 issues). Contact Japan Association of Mineralogical Sciences (JAMS) c/o Graduate School of Science, Tohoku University, Sendai 980-8578, JapanＥ-mail: KYL04223@nifty.ne.jp TEL/FAX:+81-22-224-3852

Notice about photocopying:

In order to photocopy any work from this publication, you or your organization must obtain permission from the following organization which has been delegated for copyright for clearance by the copyright owner of this publication.

Except in the USA: Japan Academic Association for Copyright Clearance, Inc. (JAACC), 6-41 Akasaka 9-chome, Minato-ku, Tokyo 107-0052, Japan TEL:+81-3-3475-5618, FAX:+81-3-3475-5619 E-mail: info@jaacc.jp In the USA: Copyright clearance Center, Inc. 222 Rosewood Drive, Danvers, MA 01923, USA, Phone: (978) 750-8400, FAX: (978) 646-8600 